\title{
KINERJA PRODUKSI KEPITING BAKAU, Scylla tranquebarica PADA KETINGGIAN AIR DAN UKURAN WADAH BERBEDA
}

\author{
Muhlis $^{* *}$, Tatag Budiardi**), Irzal Effendi*), dan Yani Hadiroseyani** \\ *) Program Studi IImu Akuakultur Program Pascasarjana, Fakultas Perikanan dan IImu Kelautan, \\ Institut Pertanian Bogor \\ Kampus IPB Darmaga, Jl. Agatis, Babakan, Kec. Dramaga, Kota Bogor, Jawa Barat 16128 \\ *) Departemen Budidaya Perairan Fakultas Perikanan dan IImu Kelautan Institut Pertanian Bogor
}

(Naskah diterima: 10 Maret 2021; Revisi final: 8 September 2021; Disetujui publikasi: 8 September 2021)

\begin{abstract}
ABSTRAK
Wadah pemeliharaan merupakan hal yang perlu diperhatikan dan salah satu kunci dalam pertumbuhan, perkembangan, dan produksi kepiting bakau. Salah satu permasalahan yang dihadapi dalam budidaya kepiting bakau adalah kurang tepatnya wadah budidaya yang digunakan. Penelitian ini bertujuan untuk menentukan ukuran wadah dan ketinggian air yang tepat untuk budidaya kepiting bakau, Scylla tranquebarica dilihat dari laju pertumbuhan harian dan periode molting. Penelitian dilakukan di tambak masyarakat Desa Mulaeno Kecamatan Poleang Tengah Kabupaten Bombana Provinsi Sulawesi Tenggara. Hewan Uji berupa kepiting bakau ukuran 57,89 $\pm 2,18 \mathrm{~g} \mathrm{ekor}^{-1}$ sebanyak 54 ekor. Pemeliharaan dilakukan selama 60 hari pada wadah single room (1 ekor/wadah) pada ketinggian air berbeda 30, 50, dan $70 \mathrm{~cm}$ dengan ukuran wadah yang berbeda yakni $30 \mathrm{~cm} \times 30 \mathrm{~cm}, 40 \mathrm{~cm} \times 40 \mathrm{~cm}$, dan $50 \mathrm{~cm} \times 50 \mathrm{~cm}$. Wadah pemeliharaan yang digunakan sebanyak 54 unit terbuat dari bambu yang berbentuk seperti kandang (kerangkeng) ditempatkan scara acak pada tambak. Pakan yang diberikan berupa ikan rucah sebanyak $5 \%$ dari bobot tubuh dan diberikan pada pagi dan sore hari. Terdapat sembilan perlakuan dan diulang sebanyak enam kali, yakni P33 (ketinggian air $30 \mathrm{~cm}$, ukuran wadah $30 \mathrm{~cm} \times 30 \mathrm{~cm}$ ), P35 (ketinggian air $50 \mathrm{~cm}$, ukuran wadah $30 \mathrm{~cm} \times 30 \mathrm{~cm}$ ), P37 (ketinggian air $70 \mathrm{~cm}$, ukuran wadah $30 \mathrm{~cm} \times 30 \mathrm{~cm}$ ), P43 (ketinggian air $30 \mathrm{~cm}$, ukuran wadah $40 \mathrm{~cm} \times 40 \mathrm{~cm}$ ), P45 (ketinggian air $50 \mathrm{~cm}$, ukuran wadah $40 \mathrm{~cm} \times 40 \mathrm{~cm}$ ), P47 (ketinggian air $70 \mathrm{~cm}$, ukuran wadah $40 \mathrm{~cm} \times 40 \mathrm{~cm}$ ), P53 (ketinggian air $30 \mathrm{~cm}$, ukuran wadah $50 \mathrm{~cm} \times 50$ $\mathrm{cm}$ ), P55 (ketinggian air $50 \mathrm{~cm}$, ukuran wadah $50 \mathrm{~cm} \times 50 \mathrm{~cm}$ ), P57 (ketinggian air $70 \mathrm{~cm}$, ukuran wadah 50 $\mathrm{cm} \times 50 \mathrm{~cm}$ ). Hasil penelitian menunjukkan bahwa tidak ada interaksi antara ukuran wadah dan ketinggian air, serta tidak ada pengaruh nyata terhadap kinerja produksi kepiting bakau. Ukuran wadah $30 \mathrm{~cm} \times 30$ $\mathrm{cm}$, ketinggian air $30 \mathrm{~cm}$ (P33) lebih efektif dan efisien digunakan pada budidaya kepiting bakau menggunakan sistem single room.
\end{abstract}

\section{KATA KUNCl: kepiting bakau; ketinggian air; frekuensi molting; single room; ukuran wadah}

ABSTRACT: Production performance of mud crab, Scylla tranquebarica farmed in different cage sizes submerged at different water depths. By: Muhlis, Tatag Budiardi, Irzal Effendi, and Yani Hadiroseyani

Specifications of cage farming plays important roles in the growth, suvival, and expected harvest of farmed mud crab. One of the constraints in mud crab farming is that the cages used are not suitable or preferred for the species. The research aimed to determine the proper cage size and water depth for mud crab culture using the growth rate and molting period as the observed parameters. This research was conducted in a pond located in Mulaeno Village, Bombana Regency Central Poleang, Southeast Sulawesi province. The experiment used 54 mud crabs sized between $50-70 \mathrm{~g}$. Each crab was kept in a cage sized $30 \mathrm{~cm} \times$ $30 \mathrm{~cm}, 40 \mathrm{~cm} \times 40 \mathrm{~cm}$ or $50 \mathrm{~cm} \times 50 \mathrm{~cm}$ with a stocking density of 1 ind./cage. The cages were positioned at different water levels $(30 \mathrm{~cm}, 50 \mathrm{~cm}$, and $70 \mathrm{~cm}$ ). The cages were constructed from bamboo, rectangular in shape, and placed randomly in the pond. The feed (trash fish) was given twice daily (morning and

\# Korespondensi: Fakultas Perikanan dan IImu Kelautan,

Institut Pertanian Bogor. Kampus IPB Darmaga, Jl. Agatis,

Babakan, Kec. Dramaga, Kota Bogor, Jawa Barat 16128,

Indonesia

E-mail: muhlisaquaculture23@ gmail.com 
afternoon) as much as $5 \%$ of the crab body weight. There were nine treatments and each treatment had six replications, i.e, T33 (water depth $30 \mathrm{~cm}$, cage size $30 \times 30 \mathrm{~cm}$ ), T35 (water depth $50 \mathrm{~cm}$, cage size $30 \times 30 \mathrm{~cm}$ ), T37 (water depth $70 \mathrm{~cm}$, cage size $30 \times 30 \mathrm{~cm}$ ), T43 (water depth $30 \mathrm{~cm}$, cage size $40 \times 40 \mathrm{~cm}$ ), T45 (water depth $50 \mathrm{~cm}$, cage size $40 \times 40 \mathrm{~cm}$ ), T47 (water depth $70 \mathrm{~cm}$, cage size $40 \times 40 \mathrm{~cm}$ ), T53 (water depth $30 \mathrm{~cm}$, cage size $50 \times 50 \mathrm{~cm}$ ), T55 (water depth $50 \mathrm{~cm}$, cage size $50 \times 50 \mathrm{~cm}$ ), T57 (water depth $70 \mathrm{~cm}$, cage size $50 \times 50 \mathrm{~cm}$ ). The results showed that there wereno significant influence of the cage sizes and water depths on the production performance of the mud crab. The cage size $30 \times 30 \mathrm{~cm}$, and water depth $30 \mathrm{~cm}$ (T33) is more effective and efficient in mud crab farm using a single room system.

\section{KEYWORDS: mud crab, water depth, molting period, single room, cage size}

\section{PENDAHULUAN}

Kepiting bakau, Scylla serrata adalah organisme nokturnal yang sebagian besar siklus hidupnya berada di perairan payau khususnya di kawasan mangrove, serta memiliki sifat soliter dan kanibalisme yang tinggi. Kepiting bakau merupakan binatang krustasea yang melakukan molting untuk pertumbuhan, serta memiliki perilaku membenamkan diri di dalam lumpur dan melakukan pergerakan ke darat. Budidaya kepiting bakau sudah banyak dilakukan oleh masyarakat baik pada tambak maupun pada ekosistem mangrove. Budidaya tersebut dilakukan dengan sistem pen culture, silvofisheri, dan sistem single room. Maraknya budidaya kepiting bakau ini didasari oleh permintaan kepiting bakau yang tinggi (FAO, 2018) menyatakan bahwa permintaan kepiting dunia pada tahun 20152017 terus meningkat sangat pesat. Data dari negaranegara utama importir kepiting seperti Amerika, Cina, dan Korea menunjukkan, bahwa terjadi peningkatan impor kepiting dari 260 ribu ton per tahun menjadi 290 ribu per tahun. Permintaan kepiting yang tinggi tersebut, tidak diikuti oleh produksi kepiting yang memadai.

Budidaya kepiting bakau sistem single room atau sistem pemeliharaan secara individual telah banyak dilakukan oleh masyarakat untuk memproduksi kepiting cangkang lunak. Namun demikian, sistem ini juga sangat potensial untuk diterapkan pada budidaya pembesaran kepiting bakau. Sistem single room ini juga dapat mengatasi sifat kanibalisme dalam pemeliharaan. Hal ini sesuai dengan pendapat Quinitio \& Estepa (2011) bahwa selain ganti kulit, salinitas fluktuasi suhu, pakan, dan padat tebar, kanibalisme merupakan faktor yang secara langsung memengaruhi sintasan kepiting bakau. Menurut Mirera (2009), sistem pemeliharaan kepiting bakau secara individual pada wadah berukuran $30 \mathrm{~cm} \times 30 \mathrm{~cm}$ menghasilkan tingkat kelangsungan hidup dan pertumbuhan yang secara signifikan lebih baik dibandingkan dengan budidaya pada wadah $6 \mathrm{~m} \times 2 \mathrm{~m}$. Selain itu, ukuran wadah memberikan pengaruh terhadap pertumbuhan kepiting bakau dikarenakan ukuran wadah akan menimbulkan dampak stres pada kepiting bakau dan juga permasalahan efisiensi ruang yang terkait dengan produktivitas. Kemudian dilihat dari aspek bisnis dan efisiensi ruang, ruang budidaya sebaiknya digunakan secara optimal untuk memaksimalkan produktivitas. Berkaitan dengan hal tersebut, Pantjara et al. (2011) menyatakan bahwa produktivitas tambak dapat ditingkatkan dengan memaksimalkan penggunaan air dan wadah dalam pemenuhan produksi secara maksimal. Penelitian ini bertujuan untuk menentukan ukuran wadah dan ketinggian air yang tepat untuk budidaya kepiting bakau, Scylla tranquebarica dilihat dari laju pertumbuhan harian dan periode molting.

\section{BAHAN DAN METODE}

Penelitian ini dilaksanakan di tambak masyarakat dari bulan Agustus sampai bulan Oktober 2017 bertempat di Desa Mulaeno Kecamatan Poleang Tengah Kabupaten Bombana Provinsi Sulawesi Tenggara.

\section{Materi Uji}

Organisme uji yang digunakan adalah kepiting bakau, Scylla sp. dengan bobot awal 57,89 $\pm 2,18 \mathrm{~g}$ ekor ${ }^{-1}$ sebanyak 54 ekor yang diperoleh dari seleksi tangkapan nelayan setempat. Kepiting yang digunakan dalam penelitian ini adalah kepiting sehat yang ditandai dengan respons yang agresif pada saat dipegang (Kanna, 2002). Organisme uji diaklimatisasi selama tujuh hari kemudian dipelihara selama 60 hari dalam wadah penelitian dari bambu yang berbentuk seperti kandang (kerangkeng) yang ditempatkan secara acak pada tambak. Pemeliharaan dilakukan dengan single room (1 ekor/wadah) pada ketinggian air berbeda yaitu 30, 50, dan $70 \mathrm{~cm}$ dari permukaan air tambak dan ukuran wadah yang berbeda yakni $30 \mathrm{~cm}$ $\times 30 \mathrm{~cm}, 40 \mathrm{~cm} \times 40 \mathrm{~cm}$, dan $50 \mathrm{~cm} \times 50 \mathrm{~cm}$, kemudian diletakkan secara acak dalam tambak dengan keadaan terapung dan masing-masing wadah berada di atas permukaan air. Ketinggian air di tambak adalah 100 $\mathrm{cm}$, Tinggi wadah menyesuaikan ketinggian air setiap wadah, sehingga dihasilkan akumulasi wadah menjadi ukuran wadah P33 (ketinggian air $30 \mathrm{~cm}$, ukuran wadah $30 \mathrm{~cm} \times 30 \mathrm{~cm}$ ), P35 (ketinggian air $50 \mathrm{~cm}$, ukuran wadah $30 \mathrm{~cm} \times 30 \mathrm{~cm}$ ), P37 (ketinggian air $70 \mathrm{~cm}$, ukuran wadah $30 \mathrm{~cm} \times 30 \mathrm{~cm}$ ), P43 (ketinggian air 30 $\mathrm{cm}$, ukuran wadah $40 \mathrm{~cm} \times 40 \mathrm{~cm}$ ), P45 (ketinggian air $50 \mathrm{~cm}$, ukuran wadah $40 \mathrm{~cm} \times 40 \mathrm{~cm}), \mathrm{P} 47$ 
(ketinggian air $70 \mathrm{~cm}$, ukuran wadah $40 \mathrm{~cm} \times 40 \mathrm{~cm}$ ), P53 (ketinggian air $30 \mathrm{~cm}$, ukuran wadah $50 \mathrm{~cm} \times 50$ $\mathrm{cm}$ ), P55 (ketinggian air $50 \mathrm{~cm}$, ukuran wadah $50 \mathrm{~cm}$ $x 50 \mathrm{~cm}$ ), P57 (ketinggian air $70 \mathrm{~cm}$, ukuran wadah 50 $\mathrm{cm} \times 50 \mathrm{~cm}$ ). Pergantian air tambak dilakukan setiap hari dengan tetap memperhatikan ketinggian air sesuai dengan perlakuan pada penelitian. Pemberian pakan dilakukan pada pagi dan sore hari. Analisis dan tabulasi data akan dilakukan menggunakan program SPSS dengan tabel Anova dan uji lanjut DMRT.

\section{Rancangan Percobaan}

Penelitian ini dirancang menggunakan rancangan acak lengkap (RAL) faktorial yang terdiri atas faktor ukuran wadah $30 \mathrm{~cm} \times 30 \mathrm{~cm}, 40 \mathrm{~cm} \times 40 \mathrm{~cm}, 50 \mathrm{~cm} \times$ $50 \mathrm{~cm}$ dan faktor ketinggian air $30 \mathrm{~cm}, 50 \mathrm{~cm}$, dan 70 $\mathrm{cm}$ masing-masing diulang enam kali.

\section{Teknik Budidaya}

Kepiting bakau yang telah dipilih ditimbang bobot dan ukuran karapas awalnya. Penimbangan bo bot tubuh kepiting bakau dilakukan dengan menggunakan timbangan dengan ketelitian $0,01 \mathrm{~g}$. Pengukuran panjang dan lebar karapas dilakukan dengan menggunakan jangka sorong dengan ketelitian $0,1 \mathrm{~cm}$. Benih yang digunakan adalah hasil tangkapan dari alam yang telah diseleksi dengan bobot 57,89 $\pm 2,18 \mathrm{~g}$ ekor ${ }^{-1}$. Kriteria benih yang digunakan adalah cangkang keras, agresif (selalu berusaha menyerang bila dipegang), pada bagian mulut tidak berbusa baik pada tempat kering maupun basah, tidak cacat tubuh dalam hal ini organ tubuhnya lengkap (Kanna, 2002). Pemberian pakan dilakukan setiap hari, lama pemeliharaan adalah 60 hari mulai dari September sampai Oktober 2017. Penimbangan dan pengukuran karapas kepiting bakau dilakukan setiap dua minggu sekali.

Pakan yang diberikan berupa ikan rucah segar, sebanyak 5\%dari bobot tubuh setiap harinya. Pakan diberikan sebanyak dua kali sehari pada pagi dan sore hari. Panen dilakukan setelah lama pemeliharaan mencapai 60 hari. Pada saat panen dilakukan penimbangan bobot total.

\section{Parameter Uji}

Parameter uji meliputi laju pertumbuhan spesifik (LPS), periode molting (FM), rasio konversi pakan (RKP), dan tingkat kelangsungan hidup (TKH). Rumus yang digunakan:

Laju pertumbuhan spesifik (Zonneveld et al., 1991)

$$
\text { LPS }\left(\% \text { ari }^{-1}\right)=\frac{(\text { In bobot } r \text { ataan akhir }- \text { awal })}{\text { Waktu pemelihara an }} \times 100 \%
$$

Tingkat kelangsungan hidup (Effendie, 1997)

$$
\text { TKH }(\%)=\frac{\text { Jumlah akhir }}{\text { Jumlah awal }} \times 100
$$

Rasio konversi pakan (Zonneveld et al., 1991)

$$
\text { RKP }=\frac{\text { Jumlah pakan }}{(\text { Biomassa akhir }- \text { biomassa awal })}
$$

Pengamatan molting kepiting bakau pada penelitian ini dilihat dan dihitung setiap hari dari jumlah kepiting yang mengalami molting dan waktu molting tiap individu kepiting bakau pada masingmasing perlakuan. Pengamatan jumlah kepiting yang molting dihitung secara visual berdasarkan jumlah morfologi kepiting yang molting. Waktu molting merupakan waktu yang dibutuhkan oleh kepiting bakau untuk melakukan proses regenerasi karapas. Waktu tersebut dihitung berdasarkan kisaran waktu molting sejak molting pertama sampai molting terakhir di akhir penelitian. Kesempurnaan molting ditandai dengan mengamati kelengkapan capit dan kaki jalan kepiting bakau pada semua perlakuan, baik yang sempurna maupun yang tidak sempurna.

\section{Analisis Data}

Data yang diperoleh dianalisis menggunakan analisis ragam (ANOVA). Jika hasil analisis menunjukkan

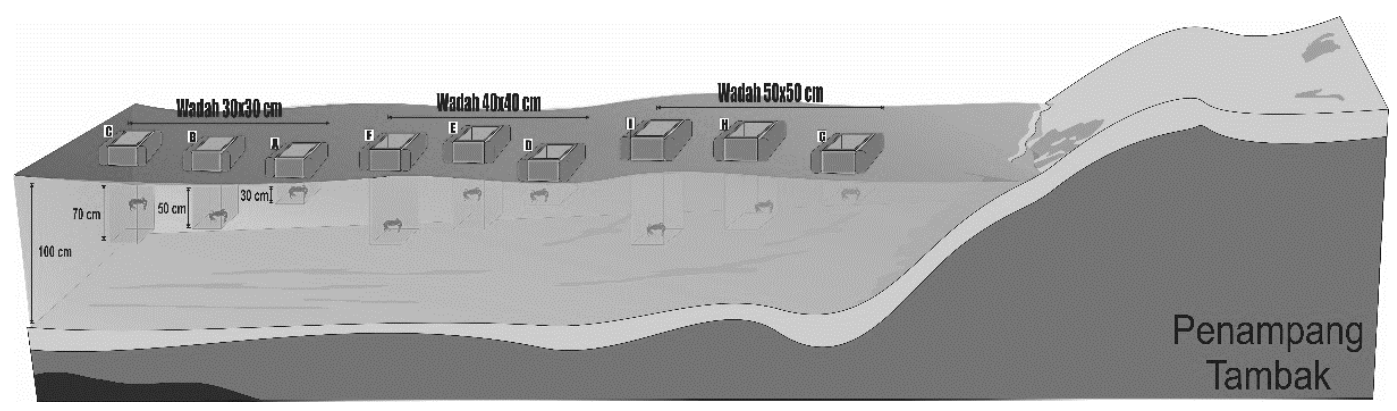

Gambar 1. Pangaturan letak kerangkeng pada kedalaman yang berbeda di tambak.

Figure 1. Arrangement of the cages at different water depths in the pond. 
pengaruh nyata maka dilanjutkan dengan Uji Duncan pada taraf kepercayaan $95 \%(\alpha=0,05)$ (Gaspersz, 1991). Pengolahan dan analisis data menggunakan bantuan perangkat lunak Microsoft Excel 2016, Minitab 17, dan SPSS versi 22.0.

\section{HASIL DAN BAHASAN}

Hasil penelitian menunjukkan bahwa persentase laju pertumbuhan spesifik pada semua perlakuan berada pada kisaran 1,18-1,31\%hari-1. Analisis statistik menunjukkan tidak adanya interaksi antara ukuran wadah dan ketinggian air. Hasil analisis statistik juga menunjukkan tidak ada perbedaan yang nyata antar semua perlakuan yang diberikan ( $P>0,05)$. Grafik laju pertumbuhan spesifik selama penelitian disajikan pada Gambar 2.

Hasil penelitian laju pertumbuhan spesifik menunjukkan bahwa antara satu perlakuan dengan perlakuan yang lain tidak terdapat perbedaan yang nyata. Hal ini diduga karena kondisi lingkungan (Tabel 1) dan perlakuan yang diberikan masih dalam batas toleransi kepiting bakau. Selain itu, waktu pemeliharaan kepiting bakau yang relatif singkat juga diduga memberikan hasil yang tidak berbeda. Pertumbuhan kepiting bakau yang relatif baik ini diduga karena kondisi kepiting dalam wadah budidaya masih dalam batas toleransi terhadap stres, sehingga kepiting tidak mengalami stres. Dalam kondisi tersebut kepiting bakau dapat lebih optimal dalam mengonsumsi pakan yang diberikan. Mirera \& Mtile (2009) menyatakan bahwa pola pergerakan kepiting yang relatif sedikit pada wadah budidaya, baik dalam media yang berukuran luas maupun yang berukuran kecil, membuat kepiting dapat menyimpan energi lebih besar untuk pertumbuhan. Hal senada juga dikemukakan oleh Agus (2008) bahwa kurangnya pergerakan kepiting di dalam wadah single room dapat membuat energi untuk reproduksi dapat dikendalikan dan dapat pula meningkatkan energi untuk pertumbuhan.

Hasil penelitian ini menunjukkan bahwa persentase periode molting pada semua perlakuan berada pada 13-16 hari. Analisis statistik menunjukkan tidak adanya interaksi antara ukuran wadah dan ketinggian air. Hasil analisis statistik juga menunjukkan tidak ada perbedaan yang nyata antar semua perlakuan yang diberikan $(P>0,05)$. Grafik periode molting selama penelitian disajikan pada Gambar 3.

Periode molting kepiting bakau selama penelitian tidak memberikan pengaruh nyata, ini dikarenakan periode molting sejalan dengan pertumbuhan kepiting bakau. Pertumbuhan kepiting erat kaitannya dengan frekuensi molting. Jumlah molting memengaruhi pertumbuhan pada kepiting bakau. Setiap terjadi molting ukuran kepiting meningkat diiringi dengan pertambahan bobot kepiting bakau (Fatihah et al.,

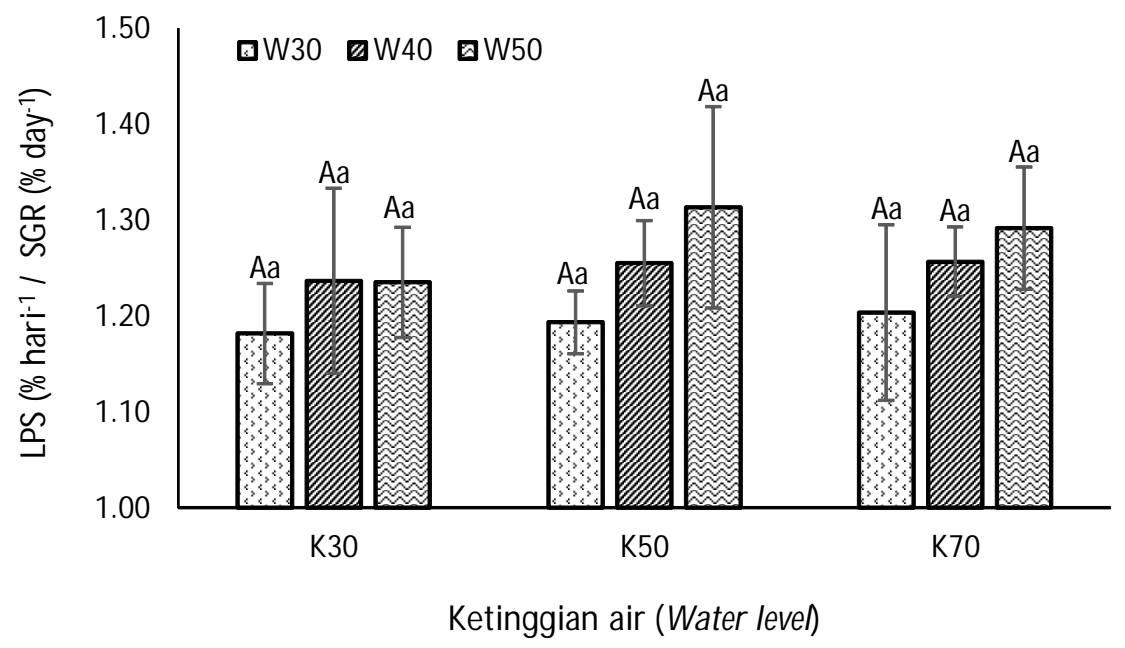

Gambar 2. Laju pertumbuhan spesifik kepiting bakau selama penelitian (huruf kapital yang sama menunjukkan tidak beda nyata pada ketinggian air dengan taraf kepercayaan 95\% huruf kecil yang sama menunjukkan tidak beda nyata pada ukuran wadah dengan taraf kepercayaan 95\% Tidak terdapat interaksi antara ukuran wadah dan ketinggian air).

Figure 2. Spesific growth rate of mud crab during the research (the same capital letter shows no significant difference in water depth with a confidence level of $95 \%$ the same lowercase letter shows no significant difference in the cage sizes at a confidence level of $95 \%$ There is no interaction between cage sizes and water depth). 


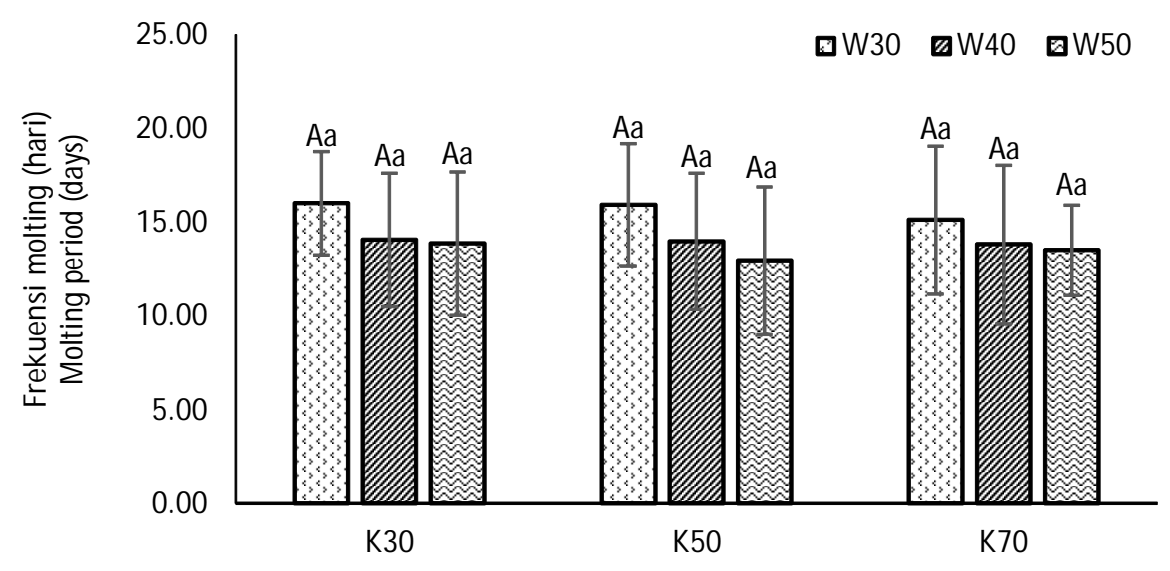

Ketinggian air (Water level)

Gambar 3. Periode molting kepiting bakau selama penelitian (huruf kapital yang sama menunjukkan tidak beda nyata pada ketinggian air dengan taraf kepercayaan $95 \%$ huruf kecil yang sama menunjukkan tidak beda nyata pada ukuran wadah dengan taraf kepercayaan 95\% Tidak terdapat interaksi antara ukuran wadah dan ketinggian air).

Figure 3. Molting period of mud crab during the research (the same capital letter shows no significant difference in water depth at a confidence level of $95 \%$ the same lowercase letter shows no significant difference in the cage sizes at a confidence level of $95 \%$ There is no interaction between cage sizes and water depth).

2017). Selaras dengan laju pertumbuhan kepiting kondisi lingkungan, perlakuan yang diberikan masih dalam batas toleransi dan waktu penelitian yang relatif singkat sehingga perlakuan tidak memberikan pengaruh yang nyata terhadap periode molting.

Hasil penelitian ini menunjukkan bahwa persentase rasio konversi pakan pada semua perlakuan berada pada kisaran 1,70-1,91. Analisis statistik menunjukkan tidak adanya interaksi antara ukuran wadah dan ketinggian air dalam memengaruhi rasio konversi pakan. Hasil analisis statistik juga menunjukkan tidak ada perbedaan yang nyata antar semua perlakuan yang diberikan $(P>0,05)$. Grafik rasio konversi pakan selama penelitian disajikan pada Gambar 4.

Untuk mengetahui efektivitas dan pemanfaatan pakan yang dikonsumsi selama masa pemeliharaan organisme uji dapat dilakukan dengan menghitung rasio konversi pakan (RKP). Dalam penelitian ini tidak adanya perbedaan yang nyata antara perlakuan yang satu dengan yang lainnya dikarenakan tidak adanya persaingan kepiting bakau dalam mengonsumsi atau memperoleh makanan. Nilai RKP tertinggi terdapat pada ukuran wadah $30 \mathrm{~cm} \times 30 \mathrm{~cm}$ dan ketinggian air $30 \mathrm{~cm}$ yakni 1,91 dan terendah pada ukuran wadah 50 $\mathrm{cm} \times 50 \mathrm{~cm}$ dan ketinggian air $50 \mathrm{~cm}$ yakni 1,70 . Hal ini sesuai dengan penelitian yang dilakukan oleh Morales \& Barba (2015) yang menghasilkan RKP pada kepiting bakau sebesar 1,7 jika menggunakan pakan ikan rucah dan 1,2 jika menggunakan pakan keong emas. RKP meningkat seiring dengan peningkatan bobot tubuh kepiting (Mandal et al., 2017).

Hasil penelitian ini menunjukkan bahwa persentase tingkat kelangsungan hidup pada semua perlakuan adalah $100 \%$ Analisis statistik menunjukkan tidak adanya interaksi antara ukuran wadah dan ketinggian air yang memengaruhi sintasan kepiting bakau $(P>0,05)$. Grafik tingkat kelangsungan hidup selama penelitian disajikan pada Gambar 5.

Tingkat kelangsungan hidup kepiting bakau pada umumnya berkisar antara $50 \% 90 \% \mathrm{Hal}$ ini disebabkan oleh sifat kanibalisme kepiting bakau yang sangat tinggi yang dapat menurunkan produksi kepiting bakau dalam suatu kondisi budidaya. Dengan demikian kepiting bakau tidak dapat hidup bersama dalam satu ruang atau wadah dengan kondisi kompetisi yang tinggi terhadap ruang dan wilayah teritorial. Salah satu penyebab tingginya kanibalisme dalam budidaya kepiting bakau adalah kompeitisi ruang. Hal tersebut sesuai dengan Kuntari (2017) yang menyatakan bahwa padat tebar 15 ekor kepiting bakau dalam satu wadah berukuran $60 \mathrm{~cm} \times 40 \mathrm{~cm} \times 40 \mathrm{~cm}$ meyebabkan rendahnya tingkat kelangsungan hidup kepiting bakau yang disebabkan oleh aktivitas kanibalisme kepiting bakau. Untuk itu, dalam proses budidaya kepiting bakau untuk menghasilkan tingkat kelangsungan hidup yang tinggi dan maksimal $(100 \%$ perlu dilakukan suatu 


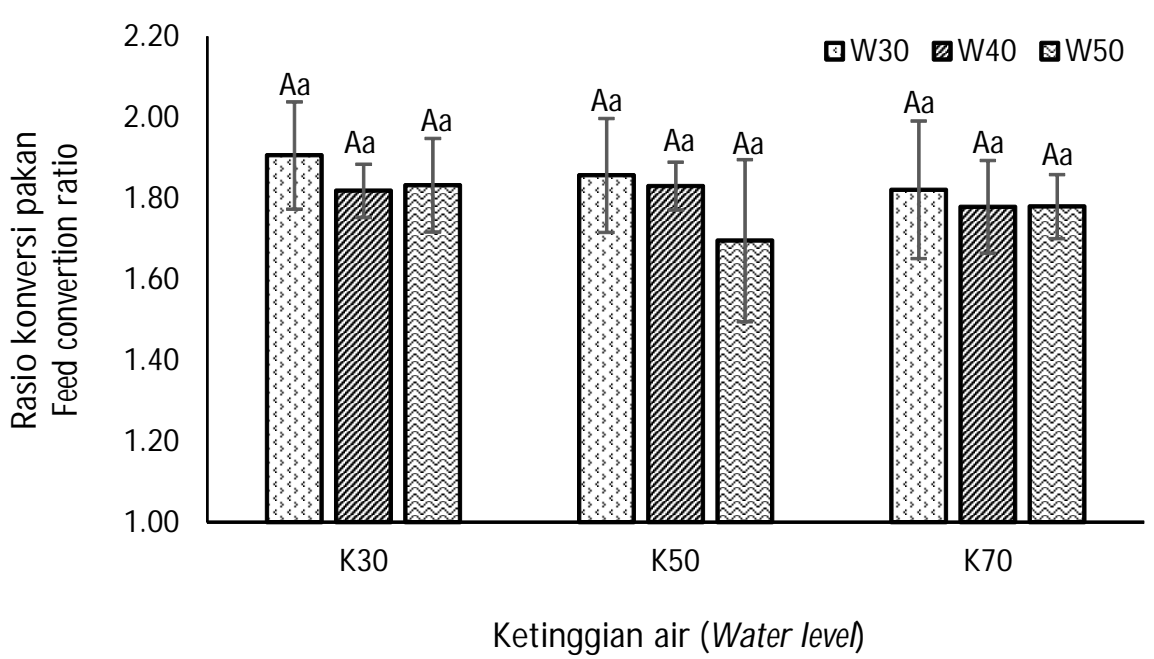

Gambar 4. Rasio konversi pakan kepiting bakau selama penelitian (huruf kapital yang sama menunjukkan tidak beda nyata pada ketinggian air dengan taraf kepercayaan 95\% huruf kecil yang sama menunjukkan tidak beda nyata pada ukuran wadah dengan taraf kepercayaan 95\% Tidak terdapat interaksi antara ukuran wadah dan ketinggian air).

Figure 4. Feed convertion ratio of mud crab during the research (the same capital letter shows no significant difference in water depth with a confidencelevel of 95\% the samelowercase letter shows no significant difference in the cage sizes at a confidence level of $95 \%$ There is no interaction between cage sizes and water depth).

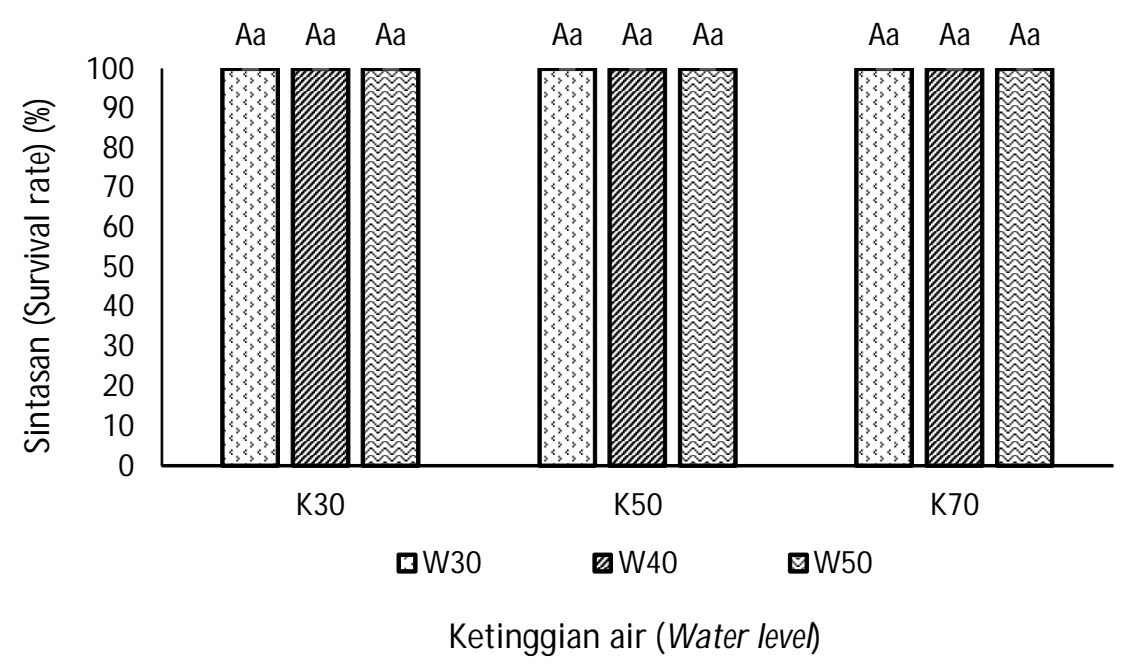

Gambar 5. Tingkat kelangsungan hidup kepiting bakau selama penelitian (huruf kapital yang sama menunjukkan tidak beda nyata pada ketinggian air dengan taraf kepercayaan 95\% huruf kecil yang sama menunjukkan tidak beda nyata pada ukuran wadah dengan taraf kepercayaan 95\% Tidak terdapat interaksi antara ukuran wadah dan ketinggian air).

Figure 5. Survival rate of mud crab during research (the same capital letter shows no significant difference in water epth with a confidence level of 95\% the same lowercase letter shows no significant difference in the cage sizes at a confidence level of $95 \%$ There is no interaction between cage sizes and water depth).

metode yang lebih baik. Menurut Zhao et al. (2015); Laranja et al. (2010), pemeliharaan kepiting bakau satu ekor dalam setiap wadah, mengurangi padat tebar, dan memberikan pakan yang cukup merupakan strategi yang dilakukan pembudidaya dalam mengurangi kanibalisme hingga didapatkan tingkat kelangsungan hidup yang maksimal. Hal tersebut terbukti dari hasil penelitian ini yang menghasilkan tingkat kelangsungan 
Tabel 1. Parameter fisika kimia air tambak selama pemeliharaan

Table 1. Measured water quality parameters in the pond during the research period

\begin{tabular}{lcccc}
\hline \multicolumn{1}{c}{$\begin{array}{c}\text { Parameter } \\
\text { Param eters }\end{array}$} & $\begin{array}{c}\text { Rentang } \\
\text { Range }\end{array}$ & $\begin{array}{c}\text { Rataan } \\
\text { Average }\end{array}$ & $\begin{array}{c}\text { Standar deviasi } \\
\text { Standard deviation }\end{array}$ & $\begin{array}{c}\text { Standar kelayakan } \\
\text { Suitability standard }\end{array}$ \\
\hline Suhu (Temperature) $\left({ }^{\circ} \mathrm{C}\right)$ & $25.5-35.2$ & 29.88 & 3.3 & $25-30$ \\
Kecerahan (Hardness) $(\mathrm{cm})$ & $38-40$ & 39.33 & 0.79 & $47-58$ \\
TDS (mg L ${ }^{-1}$ ) & $14.8-21.5$ & 18.3 & 3.4 & $0.1-20$ \\
TSS (mg L & $52.3-85.1$ & 68.9 & 16.4 & $27.9-142.4$ \\
Substrat (Substrate): & & & & \\
a. Tekstur (Texture) & Debu (Ash) & - & - & - \\
b. Nitrogen (Nitrogen) (\%) & $0.33-0.63$ & 0.43 & 0.17 & $0.15-0.50$ \\
C. Fosfor (Phosphor) (mg/L) & $4.71-54.08$ & 41.17 & 32.02 & $13.28-67.34$ \\
Salinitas (Salinity) (ppt) & $19.90-34.40$ & 33.36 & 1.43 & $18.73-33.90$ \\
pH & $6.9-7.7$ & 7.04 & 0.15 & $7.5-8.5$ \\
Oksigen terlarut (Dissolved & $5.4-7.8$ & 6.64 & 0.48 & 5.51 \\
Amonia (Ammonia) (mg L ${ }^{-1}$ ) & $0.04-0.06$ & 0.05 & 0.01 & $<0.2$ \\
Nitrit (Nitrite) (mg L-1 $)$ & $0.005-0.047$ & 0.03 & 0.02 & $<0.1$ \\
\hline
\end{tabular}

hidup sebesar $100 \%$ pada semua perlakuan (Gambar 5). Parameter fisika kimia perairan tambak dalam penelitian mendukung kehidupan petumbuhan kepiting.

\section{KESIMPULAN}

Ukuran wadah dan ketinggian air pada sistem single room tidak mengakibatkan perbedaan pada kinerja produksi budidaya kepiting bakau berdasarkan pertumbuhan, periode molting, rasio konversi pakan, dan tingkat kelangsungan hidup. Dilihat dari segi efisiensi dan efektivitas, ukuran wadah $30 \mathrm{~cm} \times 30$ $\mathrm{cm}$, ketinggian air $30 \mathrm{~cm}$ (P33) merupakan dimensi ruang terbaik yang dapat dipilih pada budidaya kepiting bakau menggunakan sistem single room. Hal ini, dikarenakan efisiensi ruang pembudidayaan yang lebih optimal sehingga populasi kepiting bakau yang dibudidayakan persatuan luas tambak lebih tinggi, serta biaya produksi lebih kecil dibandingkan dengan ukuran wadah yang lain.

\section{UCAPAN TERIMA KASIH}

Terima kasih yang sebesar-besarnya kepada Lembaga Pengelola Dana Pendidikan (LPDP) Kementerian Keuangan Republik Indonesia atas bantuan beasiswa dan dana penelitian.

\section{DAFTAR ACUAN}

Agus, M. (2008). Analisis carryng capacity tambak pada sentra budi daya kepiting bakau (Scylla sp.) di Kabupaten Pemalang - Jawa Tengah. Tesis. Universitas Diponegoro, $110 \mathrm{hlm}$.
Effendie, M.I., (1997). Biologi perikanan. Yogyakarta (ID): Yayasan Pustaka Nusantara, $163 \mathrm{hlm}$.

Food and Agriculture Organization of United Nation [FAO]. (2018). Globefish highlights: A quarterly update on world seafood markets. Rome (IT): FAO, p. 63-65.

Fatihah, S.N., Julin, H.T., \& Chen, C.A. (2017). Survival, growth, and molting frequency of mud crab Scylla tranquebarica juveniles at different shelter conditions. AACL Bioflux, 10(6), 1581-1589.

Gaspersz, V. (1991). Metode perancangan percobaan untuk ilmu-ilmu pertanian, ilmu-ilmu teknik dan biologi. Bandung : CV Armico, $447 \mathrm{hlm}$.

Kanna, I. (2002). Budidaya kepiting bakau pembenihan dan pembesaran. Yogyakarta: Kanisius, $80 \mathrm{hlm}$.

Kuntari, W.B. (2017). Padat tebar optimal pada peningkatan produksi kepiting bakau Scylla sp. dalam sistem resirkulasi. Skripsi. Bogor. Institut Pertanian Bogor, 36 hlm.

Laranja, J.L.Q., Quinitio, E.T., Catacutan, M.R., \& Coloso, R.M. (2010). Effect of dietary I-tryptophan on the agonistic behavior, growth, and survival of juvenile mud crab Scylla sp. Aquaculture, 310, 84-90.

Mandal, A., Das, S.K., \& Majumder, A. (2017). Studies on physico-chemical environment and management of crab (Scylla sp.) farming in 24 Parganas (West Bengal). Indian Journal Animal Research, 3224, 1-8. 
Mirera, D.O. (2009). Trends in exploitation, development and management of artisanal mud crab (Scylla sp. Forsskal-1775) fishery and small-scale culture in Kenya: An overview. Ocean and Coastal Management, 54, 844-855.

Mirera, D.0. \& Mtile, A. (2009). A preliminary study on the response of mangrove mud crab (Scylla $\mathrm{sp}$.) to different feed types under drivein cage culture system. Journal of Ecology and Natural Environment, 1, 07-14.

Morales, M.I. \& Barba, R.B. (2015). Effects of photoperiod, water levels and sex on the feeding efficiency and weight increment of mud crabs (Scylla sp. Forskall) in a crab-fattening culture system. International Journal of Fisheries and Aquatic Studies, 3, 320-324.

Pantjara, B., Nawang, A., \& Insan, I. (2011). Peningkatan produktivitas tambak melalui budidaya perikanan terpadu. Prosiding Forum Inovasi Teknologi Akuakultur, hlm. 539-546. Bali, Indonesia: Pusat Penelitian dan Pengembangan Perikanan Budidaya.

Quinitio, E.T. \& Estepa, F.D.P. (2011). Survival and growth of mud crab, Scylla sp., juveniles subjected to removal or trimming of chelipeds. Aquaculture, $318,229-234$.

Zhao, J., Wen, X., Li, S., Zhu, D., \& Li, Y. (2015). Effects of dietary lipid levels on growth, feed utilization, body composition and antioxidants of juvenile mud crab Scylla paramamosain (Estampador). Aquaculture, 435, 200-206.

Zonneveld, N.E., Huisman, A., \& Boon, J.H. (1991). Prinsip-prinsip budidaya ikan. Jakarta (ID): PT. Gramedia Pustaka Utama, hlm. 285. 